\title{
Chironomus strenzkei FitTKAU, 1968 is A JUNior SYNONYM OF $C$. STRIATIPENNIS KIEFFER, 1910
}

\author{
Jon Martin \\ Biosciences 5, School of Biosciences, The University of Melbourne 3010, VIC Australia \\ Email:j.martin@unimelb.edu.au
}

\begin{abstract}
Two species of Chironomus with essentially identical adult wing patterns, C. strenzkei and C. striatipennis, have been reported from Brazil. Specimens were collected from the same region in the Manaus area some 50 years apart. Morphological, cytological and DNA Barcode comparisons all confirm that these two species are inseparable on any of the characteristics studied. Moreover, for the mitochondrial COI region investigated, the sequences are completely identical, and polytene chromosome banding patterns are shared between C. strenzkei and C. striatipennis populations from Japan. I therefore argue that the former species must be a junior synonym of $C$. striatipennis. As a result of the synonymy, $C$. striatipennis now becomes a new record for California and North America, and hence has a Holarctic distribution. The DNA sequence comparisons suggest that the Brazilian population may have derived from China, rather than Korea as suggested previously, and that the Californian population may not have been introduced from South America, but could equally likely have come from Asia.
\end{abstract}

\section{Introduction}

In the 1960s, while researching in the area of Manaus, Amazonas, Brazil, Fittkau collected a species of Chironomus with patterned wings, a life cycle of about 10 days and amenable to being maintained as a laboratory colony. Such a colony was maintained in the laboratories at Plön, Germany for some years, with material being distributed for study of various aspects of its biology (Syrjämäki 1965, 1967, Platzer 1967, Platzer-Schultz 1968a, b, 1970, Platzer-Schultz and Welsch 1969). Some of these studies were published before Fittkau formally described the species as C. strenzkei in 1968 (Fittkau 1968). Wülker and Morath (1989) studied the polytene chromosomes noting that it belonged to the pseuothummi-cytocomplex with arm combination AE, BF, CD, G, but stating that the banding patterns showed no similarity to the other South American species they were studying. Subsequently Sublette and Mulla (2000) reported C. strenzkei from California on the basis of adult morphology, assuming it to be a recent migrant be- cause it had not been collected in previous extensive surveys in the area.

About 40 years later, a Brazilian group collected specimens with patterned wings from the vicinity of Manaus (Amora et al. 2015). This material also had a life cycle of about 10 days and has been maintained in the laboratory since 2011 . The species was identified initially as $C$. kiiensis Tokunaga, 1936 (Lacerda et al. 2014) on the basis of morphological studies of adults, pupae and larvae from the colony, and the mitochondrial COI DNA barcode region of 2 larvae and an adult by Amora et al. (2015). The latter authors used both the name C. kiiensis and C. striatipennis Kieffer, 1910, following the results of Pramual et al. (2016) who synonymised these two species. The COI results suggested that this Brazilian population had originated from Asia, probably from somewhere near Korea in recent times (Amora et al. (2015). At no stage was $C$. strenzkei mentioned despite the fact that it had been collected in the same area and the holotype and 5 paratypes are in the National Institute for Research in Amazonia (INPA) (Fittkau 1968), where the C. striatipennis colony is situated.

The similarity between the description of the two species, and their occurrence in the same general area, suggested that a detailed analysis should be undertaken to determine whether there were two quite similar species, or whether both collections referred to the same species, in which case the $\mathrm{Ki}$ effer name would have precedence.

\section{Material and methods}

Chironomus strenzkei: Fourth instar larvae and a reared adult male from the original Plön colony were provided by Dr. Frieder Reiss in 1970. Some salivary gland polytene chromosome squashes and slide mounts of larvae and the reared adult were made at that time. The remaining larvae were fixed in modified Carnoy's fixative ( 3 parts absolute ethanol: 1 part glacial acetic acid) and stored in a freezer at $-20^{\circ} \mathrm{C}$ until the present time when three specimens were used for molecular analysis. It should be noted that these specimens had been reared at $25^{\circ} \mathrm{C}$, which is not ideal for the study of 
polytene chromosomes. Dr. Martin Spies provided five polytene chromosome squashes made from larvae from the original Plön stock by Dr. Wolfgang Wülker, and which had been lodged in the Bavarian State Collection of Zoology in Munich.

Chironomus striatipennis: Many specimens of this species have been available from many areas, particularly India, Singapore, Korea and Japan. These have been used for morphological (e.g. Chaudhuri et al. 1992; Amora et al. 2015, Martin 2017), and molecular analysis, with some limited cytological studies (Nath and Lakhotia 1989, and Gupta and Kumar 1991, Martin 2017). Those used for molecular analysis are listed in Pramual et al. (2016) and confirmed the conclusion from morphological and cytological studies, that C. kiiensis (group B of Kondo et al. 2016) was a junior synonym of $C$. striatipennis. Kondo et al. (2016) considered only the Barcode sequences and concluded from these that they were identical or close relatives. Adults had been made available to Amora et al. (2015) for their studies, so were not available for further study.

Aside from chromosome squashes made from available larval material, Dr. Sumitra Saxena kindly made available her maps of the species with details of the extensive chromosomal polymorphism present in the Indian populations.

No larvae were available from Korea or China and the only specimens from Japan, kindly supplied by Dr. Koichiro Kawai, were mostly mid fourth instars, fixed in ethanol, and so not ideal for chromosomal analysis. However from 4 larvae, the banding patterns of some arms were sufficient to enable comparison with those of specimens identified as C. strenzkei.

Morphology: The morphology of all life stages of C. striatipennis has been well examined by Chaudhuri et al. (1992) and Amora et al. (2015), and as C. kiiensis by Sasa (1978); Sasa and Hasegawa (1983), with the identification problems raised by Pramual et al. (2016). The results are integrated by Martin (2017). Data from three additional Indian adult males is also included. The morphology of C. strenzkei was included in Fittkau (1968), with some additional specimens ( 1 adult male, 5 larvae) studied by the author.

Cytogenetical examination: Salivary gland chromosome squashes were prepared by the usual method (Martin et al. 2006), or had been prepared by W. Wülker, and suitable chromosomes were photographed on an Olympus Vanox microscope on film or as digital images. No clear photographs could be obtained for arm $\mathrm{C}$.
Molecular analysis: Genomic DNA of the three larvae noted above was amplified by polymerase chain reaction (PCR), as Martin et al. (2007) for the "BARCODE" region of the mitochondrial cytochrome c oxidase subunit I (COI) gene using the Folmer et al. (1994) primers: LCO1490 (5'-GGTCAACAAATCATAAAGATATTGG-3') and HCO2198 (5'-TAAACTTCAGGGTGACCAAAAAATCA-3'). PCR products were sent to Macrogen Inc. Seoul, Republic of Korea for sequencing, the resulting sequences being submitted to GenBank: Accession numbers KY454622-24.

Sequences were compared to some available in GenBank - those of Amora et al. (2015) (Acc. nos. KJ424334-336, as C. kiiensis), sequences from Korea and Japan (JF412086, KC407765 (as C. kiiensis), and MFD034354 (BOLD acc. COTW00808 - a $C$. striatipennis specimen used for cytology), including one of the divergent Korean ' $C$. kiiensis' sequences (JQ350720) and a more recent accession from China (KP902735), not studied by Amora et al. (2015). It was not considered necessary to duplicate all the samples used by Amora et al. (2015) as there is no reason to believe those results were incorrect and the scope of this analysis is essentially a comparison of the Brazilian sequences. Uncorrected and Kimura 2-paramter (K2P) pairwise distances were obtained using PAUP* v.4.10b (Swofford 2002), but only the uncorrected distances are presented in Table 1 since there was no significant difference between the two sets of results.

\section{Results and discussion}

Morphology

The morphology of Brazilian specimens of $C$. striatipennis and $C$. strenzkei cannot be directly compared because Amora et al. (2015) only make general comments on the morphology of their specimens. Therefore comparisons must essentially be made to Indian specimens, since data from Japan or Korea may be confused by the inclusion of two species.

The most obvious similarity is the wing pattern. However this is not a good character for species separation because the known Chironomus species with a patterned wing ( $C$. calipterus Kieffer, $C$. striatipennis, and C. pallidinubeculosus Tokunaga), as opposed to darkening along the wing veins, have essentially the same pattern and there is more intra-specific variation in pattern than there is inter-specific variation.

Available data for the adult males is presented in Table 1, and indicates that there is overlap of all 
characters between the two species. Insufficient data exists for the adult female of $C$. striatipennis to make any meaningful comparisons.

Some comparisons are possible for the pupa and larva: For pupae, length of exuviae (4.8-7.6 mm cf. 5.5-7.6) is similar and both have pupal spurs with 1 main and 1 or 2 small subsidiary spines, but there are almost twice as many taeniae on the anal lobe in C. strenzkei. Amora et al. (2015) provide no information on the larva from their colony, so no direct comparisons are possible for specimens from the same locality. Metric comparisons are therefore of limited value due to ecological differences and the immaturity of available larvae from Japanese C. striatipennis and German C. strenz- kei colony. What can be noted is that both have a plumosus-type larva, the basal antennal segment is about three times longer than wide, the third and fifth antennal segments are about the same length, and the AR is at least 1.6; the mentum of each has a central trifid tooth of type III and the mandible is type II of Webb and Scholl (1985). The mandible of each also has an unusually long dorsal tooth, i.e. there is no readily observable distinction between larvae attributed to the two species.

\section{Cytogenetics}

Both species belong to the pseudothummi-cytocomplex, with the chromosome arm combination AE, BF, CD, G. As noted above, Wülker and Morath (1989) could see no similarity between the

Table 1. Comparison of adult male characters of C. striatipennis and C. strenzkei, based on the published data of Chaudhuri et al. (1992) and Fittkau (1968) plus four additional specimens as in text. Abbreviations as in Sæther (1980); SV type as Strenzke (1959).

\begin{tabular}{lllllllllll}
\hline & $\begin{array}{l}\text { Wing } \\
\text { length }\end{array}$ & VR & AR & $\begin{array}{l}\text { Ant. } \\
\text { LR }\end{array}$ & $\begin{array}{l}\text { Ant } \\
\text { F/T }\end{array}$ & BR & $\begin{array}{l}\text { Mid } \\
\text { LR }\end{array}$ & $\begin{array}{l}\text { Hind } \\
\text { LR }\end{array}$ & $\begin{array}{l}\text { SV } \\
\text { type }\end{array}$ & $\begin{array}{l}\text { Anal } \\
\text { point }\end{array}$ \\
\hline C. striatipennis & $1.98-$ & $1.04-$ & $2.47-$ & $1.49-$ & $1.08-$ & $2.4-$ & $0.55-$ & $0.73-$ & $\mathrm{E}(\mathrm{h})$ & $\begin{array}{l}\text { Narrow at } \\
\text { base }\end{array}$ \\
& 2.84 & 1.08 & 2.97 & 1.82 & 1.23 & 5.0 & 0.62 & 0.80 & & $\begin{array}{l}\text { Narrow at } \\
\text { C. strenzkei }\end{array}$ \\
& $1.56-$ & $1.04-$ & $2.1-$ & $1.69-$ & $1.17-$ & $2.6-$ & $0.62-$ & $0.72-$ & $\mathrm{E}(\mathrm{h})$ & $\begin{array}{l}\text { Nate } \\
\text { base }\end{array}$ \\
\hline
\end{tabular}
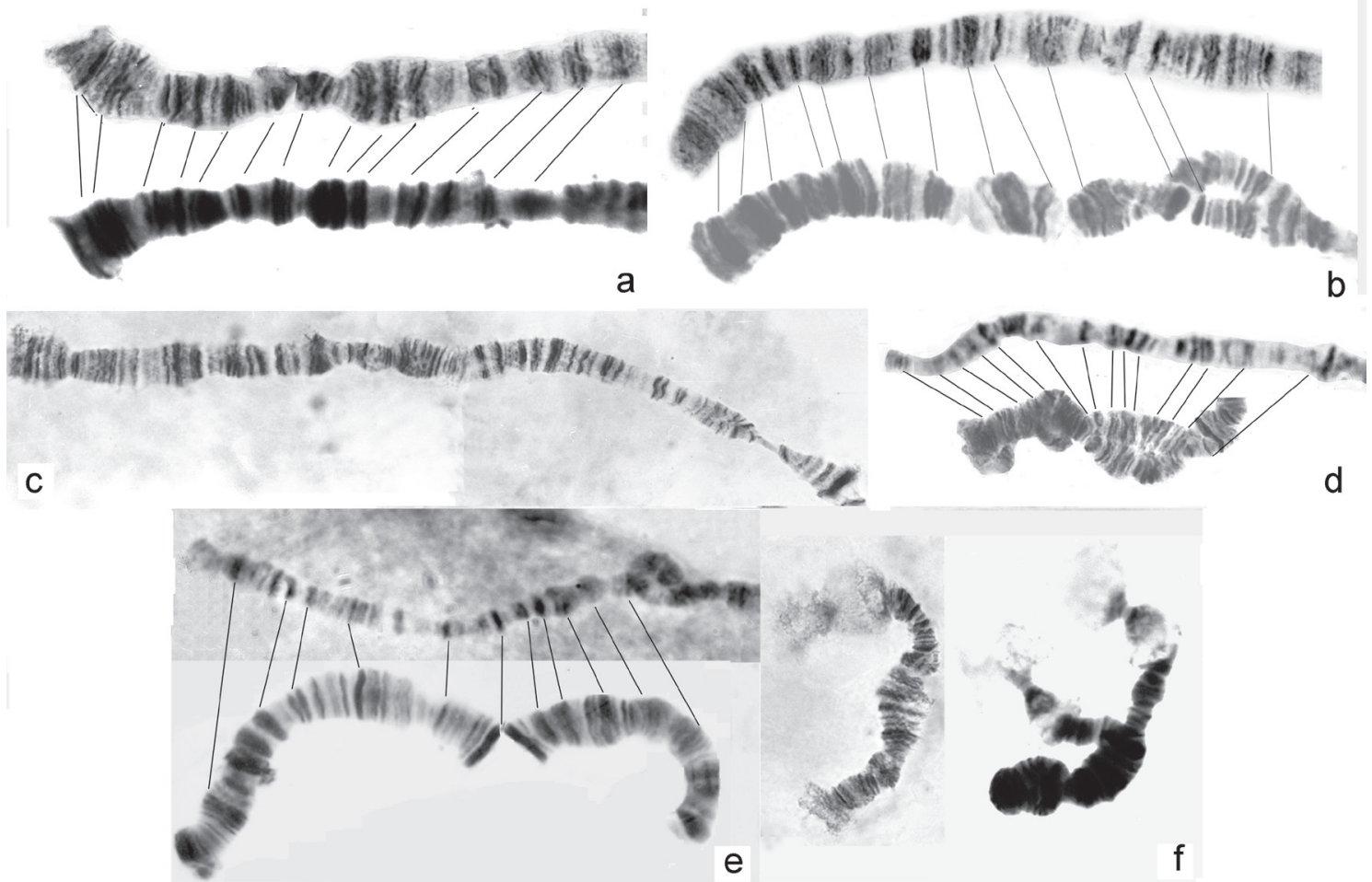

Figure 1. Comparison of polytene chromosomes of Brazilian C. strenzkei (above or left) and Japanese C. striatipennis (below or right). The centromere is to the right, except in arm $\mathrm{G}$ where it is at the top of the arm. Lines join homologous bands in the compared arms. a. Arm A, both A1.1; b. Arm E, both E1.1 (lack of pairing near centromere in Japanese specimen); c. Arm B of C. strenzkei only, B1.1; d. Arm F, both F1.1 (lack of pairing near centromere in Japanese specimen); e. Arm D, both D3.3; f. Arm G, both apparently G1.1 (only known sequence). 


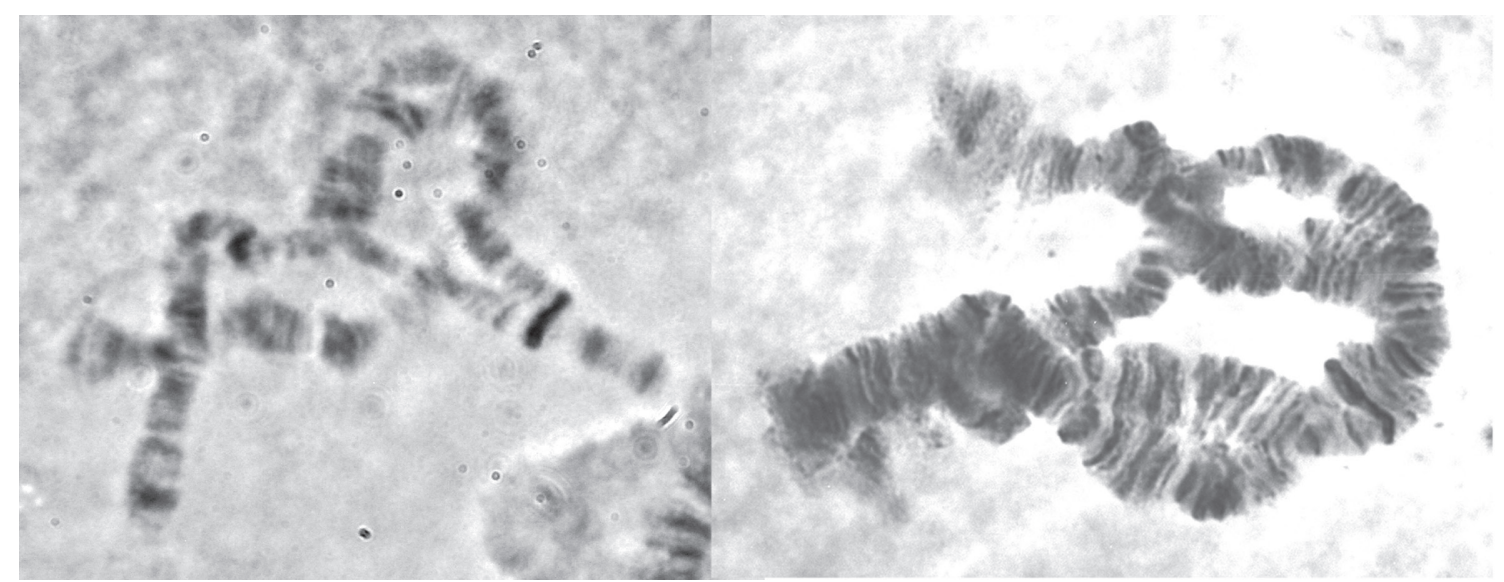

Figure 2. Heterozygotes for arm B of C. strenzkei (left) and C. striatipennis (right). It is likely that both have the sequences B1.5. The associated arm F of C. striatipennis is the same chromosome as Fig. 1,d.

banding patterns of C. strenzkei and those of the other South American species they were studying, but the banding pattern does show remarkable similarity to sequences observed in C. striatipennis, particularly those from Japan, as indicated below. Cytological comparison was difficult because of the general lack of cytological data for the Asian populations, only three descriptions from India, and the less than optimal suitability of specimens available to this study. Only Saxena (1995) has published photographs with patterns for arms A, $\mathrm{E}$ and $\mathrm{F}$ identified on the Keyl (1962) standards (as C. calipterus). Photographs provided by Saxena show that Indian populations of $C$. striatipennis are highly polymorphic (summarized in Martin 2017). In this study the banding patterns of five of the eight chromosome arms could be compared across populations. Japanese larvae investigated were heterozygous for arm B, possibly B1.5 (Fig $2 b$ ), but the actual banding patterns could not be determined with certainty. One larva from Brazil was also heterozygous for an inversion in arm B (Fig. 2a), which may well be the same sequences as seen in the Japanese specimens.

One Brazilian larva was homozygous for arm B and carried the B1 sequence (Fig. 1c). For arms A, E, D and F (Fig. 1a, b, d and e), the pattern was common across Indian and Japanese, as well as $C$. strenzkei individuals, with the sequences stpA1, stpE1, stpD3 and stpF1. It should be noted however that sequence stpE1 corresponds to a "basic sequence" of Wülker (1980) and occurs in many species across continents and in both the thummiand the pseudothummi-cytocomplexes (Kiknadze et al. 2008), so that sequence on its own would not provide evidence of species identity. The other two sequences are known only from $C$. striatipennis. It also seems likely that there are shared sequences across the three regions for arm C, where Japanese C. striatipennis and C. strenzkei both appear to have Saxena's sequence stpC4 of Indian popula-

Table 2. Uncorrected ("p") distance matrix for C. strenzkei larvae (1-3) compared with C. striatipennis from Brazil (46), China (7), Korea ( 8 \& 9), Japan (10-12) and the distinct ' $C$. kiiensis' from Korea (13). Note that sequences 4-9, 11 and 12 are entered in GenBank as the synonym C. kiiensis.

\begin{tabular}{|c|c|c|c|c|c|c|c|c|c|c|c|c|c|c|}
\hline & & 1 & 2 & 3 & 4 & 5 & 6 & 7 & 8 & 9 & 10 & 11 & 12 & 13 \\
\hline 1 & strenBrazlF & - & & & & & & & & & & & & \\
\hline 2 & strenBraz15 & 0.00000 & - & & & & & & & & & & & \\
\hline 3 & strenBraz16F & 0.00000 & 0.00000 & - & & & & & & & & & & \\
\hline 4 & kiiBraz334 & 0.00000 & 0.00000 & 0.00000 & - & & & & & & & & & \\
\hline 5 & kiiBraz335 & 0.00000 & 0.00000 & 0.00000 & 0.00000 & - & & & & & & & & \\
\hline 6 & kiiBraz336 & 0.00000 & 0.00000 & 0.00000 & 0.00000 & 0.00000 & - & & & & & & & \\
\hline 7 & kiiChinT1L & 0.00655 & 0.00654 & 0.00654 & 0.00654 & 0.00654 & 0.00654 & - & & & & & & \\
\hline 8 & kiiKorD002 & 0.00818 & 0.00817 & 0.00817 & 0.00817 & 0.00817 & 0.00817 & 0.00817 & - & & & & & \\
\hline 9 & kiigg276 & 0.00818 & 0.00817 & 0.00817 & 0.00817 & 0.00817 & 0.00817 & 0.00817 & 0.00000 & - & & & & \\
\hline 10 & striJpnJM & 0.00981 & 0.00980 & 0.00980 & 0.00980 & 0.00980 & 0.00980 & 0.00980 & 0.00163 & 0.00163 & - & & & \\
\hline 11 & kiiJpn321 & 0.08661 & 0.08660 & 0.08660 & 0.08660 & 0.08660 & 0.08660 & 0.08987 & 0.08824 & 0.08824 & 0.08824 & - & & \\
\hline 12 & kiienJpn404 & 0.08989 & 0.08987 & 0.08987 & 0.08987 & 0.08987 & 0.08987 & 0.08987 & 0.08824 & 0.08824 & 0.08824 & 0.00490 & - & \\
\hline 13 & KiienKoD 4 & 0.09805 & 0.09804 & 0.09804 & 0.09804 & 0.09804 & 0.09804 & 0.09967 & 0.09804 & 0.09804 & 0.09804 & 0.02124 & 0.01961 & - \\
\hline
\end{tabular}


tions. Arm $\mathrm{G}$ has not been mapped, but the banding patterns appear identical (Fig. 1f).

\section{Mitochondrial COI sequences}

The sequence obtained from DNA of C. strenzkei from Brazil was identical to the sequence of $C$. striatipennis from Brazil (Amora et al. 2015) and less than $1 \%$ different to the other $C$. striatipennis sequences, but $9.8 \%$ different to the divergent Korean sequence (Table 2). The closest of the Asian sequences was that from China, at $0.65 \%$.

Overall, the morphology, cytology, and particularly the COI sequences, clearly point to the conclusion that $C$. strenzkei is the same species as the one Amora et al. (2015) collected from the same region of Brazil and demonstrated to be $C$. striatipennis. Consequently the name $C$. strenzkei should be regarded as a junior synonym to $C$. striatipennis.

There are two other minor points that arise from the foregoing analysis. The inclusion of a Chinese COI sequence suggests that the Brazilian population of $C$. striatipennis may have originated from China, rather than Korea as suggested by Amora et al. (2015). The synonymy of $C$. strenzkei means that the material described by Sublette and Mulla (2000) in California is actually C. striatipennis, a new record for North America. In the absence of any DNA sequence for the Californian material, it can no longer be concluded that it was introduced from South America, as it could as easily be an independent introduction from Asia. A further consequence of this synonymy is that $C$. striatipennis now has a Holarctic distribution, although this distribution is almost certainly the result of unintentional human transport.

\section{Acknowledgements}

I am grateful to those who provided the material used in this study (see material and methods), and to Dr. Sumitra Saxena of New Delhi, India, for the photographic maps of $C$. striatipennis chromosomes with the limits of the inversions she had recognized. Some of the earlier parts of this study were supported by grants from The University of Melbourne. I also acknowledge the helpful comments of Torbjørn Ekrem and the anonymous reviewers.

\section{References}

Amora, G., Hamada, N., Lívia Maria Fusari, L.M. and Andrade-Souza, V. 2015. An Asiatic chironomid in Brazil: morphology, DNA barcode and bionomics. - ZooKeys 514: 129-144. DOI: http://dx.doi.org/10.3897/zookeys.514.9925
Chaudhuri, P.K., Das, S.K. and Sublette, J.E. 1992. Indian species of the genus Chironomus Meigen (Diptera; Chironomidae). - Zoologisches Jahrbuch für Systematik 119: 1-51.

Fittkau, E.J. 1968. Chironomus strenzkei n. sp. (Chironomidae, Dipt.), ein neues Laboratoriumstier. - Zeitschrift für Morphologie der Tiere 63: 239-250. DOI: http://dx.doi.org/10.1007/ BF00292072

Folmer, O., Black, M., Hoeh, W., Lutz, R., and Vrijenhoek, R. 1994. DNA primers for amplification of mitochondrial cytochrome $c$ oxidase subunit I from diverse metazoan invertebrates. - Molecular Marine Biology and Biotechnology 3: 294-299.

Keyl, H.-G. 1962. Chromosomenevolution bei Chironomus II. Chromosomenumbauten und phylogenetische Beziehungen der Arten. - Chromosoma 13: 464-514. DOI: http:// dx.doi.org./10.1007/BF00327342

Kieffer, J.J. 1910. Etude sur les Chironomides des Indies Orientales, avec description de quelques nouvelles espèces d'Egypte. - Memoirs of the Indian Museum 2: 181-242.

Kieffer, J.J. 1911. Descriptions de nouveaux Chironomides de l'Indian Museum de Calcutta. Records of the Indian Museum 6: 113-177.

Kiknadze, I.I., Gunderina, L.I., Butler, M.G., Wuelker,W.F., and Martin, J. 2008. Chromosomes and continents. In Dobretsov, N., Kolchanov, N., Rozanov, A., Zavarzin, G. (Eds.) Biosphere Origin and Evolution. Springer, pp. 349-369.

Kondo, N.I., Ueno, R., Ohbayashi, K., Golygina, V.V. and Takamura, K. 2016. DNA barcoding supports reclassification of Japanese Chironomus species (Diptera: Chironomidae). - Entomological Science 19: 337-350.

Lacerda, A.C.F., Gusmão, G.A. and Hamada, N. 2014 Tests of chronic and acute toxicity of crude oil on larvae of Chironomus kiiensis Tokunaga (Diptera: Chironomidae). - Brazilian Journal of Biology 74: 70-77. DOI: http:// dx.doi.org/10.1590/1519-6984.24012

Martin, J. 2017. Morphology and cytology of Oriental (Indomalayan Realm) Chironomus species. Available from: http://www.chironomidae.net/Martin/SEAChironfile/SEAChironomus.html as PDF (accessed May 2017)

Martin, J., Andreeva, E.N., Kiknadze, I.I. and Wülker, W.F. 2006. Polytene chromosomes 
and phylogenetic relationships of Chironomus atrella (Diptera: Chironomidae) in North

America. Genome 49: 1384-1392. DOI: http:// dx.doi.org/10.1139/g06-095

Martin, J., Blinov, A., Alieva, K., and Hirabayashi, K. 2007. A molecular phylogenetic investigation of the genera closely related to Chironomus Meigen (Diptera: Chironomidae) In Andersen, T (Ed.) Contributions to the systematics and ecology of aquatic Diptera A festschrift honouring Ole A. Sather. Bergen Museum Skrifter, Caddis Press. pp. 193-203.

Nath, B.B. and Lakhotia, S.C. 1989. Heat-shock response in a tropical Chironomus. Seasonal variation in response and the effect of developmental stage and tissue type on heat shock protein synthesis. - Genome 32: 676-686. DOI: http://dx.doi.org/10.1139/g89-498

Platzer, I. 1967. Untersuchungen zur Temperaturadaptation der tropischen Chironomidenart Chironomus strenzkei Fittkau (Diptera). - Zeitschrift für vergleichende Physiologie 54: 58-74. DOI: http://dx.doi.org/10.1007/ BF00298209

Platzer-Schultz, I. 1968a. Zum Problem der Bedeutung des larvalen Hämoglobins für die Atmung der tropischen Chironomide Chironomus strenzkei Fittkau (Diptera). - Zeitschrift für vergleichende Physiologie 58: 229-240. DOI: http://dx.doi.org/10.1007/BF00302638

Platzer-Schultz, I. 1968b. Zur Erholungsatmung der Larven von Chironomus strenzkei Fittkau (Diptera) mit unterschiedlichem Hämoglobingehalt. - Zeitschrift für vergleichende Physiologie 60: 269-274. DOI: http://dx.doi. org/10.1007/BF00298602

Platzer-Schultz, I. 1970. Zur Atmungsphysiologie verschiedener Entwicklungsstadien von Chironomus strenzkei Fittkau (Diptera). - Zeitschrift für vergleichende Physiologie 67: 179-185. DOI: http://dx.doi.org/10.1007/ BF00298526

Platzer-Schultz, I. and Welsch, U. 1969. Zur Entstehung und Feinstruktur der peritrophischen Membran der Larven von Chironomus strenzkei Fittkau (Diptera). - Zeitschrift für Zellforschung und mikroskopische Anatomie 100: 594-605. DOI: $\quad$ http://dx.doi.org/10.1007/ BF00344378

Pramual, P., Simwisat, K. and Martin, J. 2016. Identification and reassessment of the specific status of some tropical freshwater midges
(Diptera: Chironomidae) using DNA barcode data. - Zootaxa, 4702: 39-60. DOI: http://doi. org/10.11646/zootaxa.4072.1.2

Sæther, O.A. 1980 Glossary of chironomid morphology terminology (Diptera: Chironomidae). - Entomologia scandinavica Supplement 14: $1-51$.

Sasa, M. 1978. A comparative study of adults and immature stages of nine Japanese species of the genus Chironomus (Diptera, Chironomidae). - Research Report of the NIES 3: 1-63.

Saxena, S. 1995. Basic patterns in the chromosomal evolution of the genus Chironomus; polytene chromosomes of three Indian species C. plumatisetigerus, C. calipterus and Chironomus species. In Cranston, P.S. (Ed.) Chironomids: from Genes to Ecosystems. CSIRO Publications, Melbourne, pp. 39-48.

Sasa, M. and Hasegawa, H. 1983. Chironomid midges of the tribe Chironomini collected from sewage ditches, autrophicated ponds and some clean streams in the Ryukyu Islands, southern Japan (Diptera, Chironomidae). - Japanese Journal of Sanitary Zoology, 34: 305-341.

Strenzke, K. 1959. Revision der Gattung Chironomus MEIG. I. Die Imagines von 15 norddeutschen Arten und Unterarten. - Archiv für Hydrobiologie 56: 1-42.

Sublette, J.E. and Mulla, M.S. 2000. Chironomus strenzkei Fittkau - a new Pan-American distribution, with a review of recent similar additions to the Nearctic midges (Insecta, Diptera, Chironomidae). - Spixiana 23: 145-149.

Swofford, D.L. 2002. PAUP*, Phylogenetic Analysis Using Parsimony, Version 4. Sinauer, Sunderland, MA.

Syrjämäki, J. 1965. Laboratory studies on the swarming behaviour of Chironomus strenzkei Fittkau in litt. (Dipt., Chironomidae) I. Mechanism of swarming and mating. - Annales zoologici Fennici 2: 145-152.

Syrjämäki, J. 1967. Laboratory studies on the swarming behaviour of Chironomus strenzkei Fittkau in litt. (Dipt., Chironomidae) II. Daily rhythm of swarming during artificially changed light intensities. - Annales zoologici Fennici 4: 19-28.

Tokunaga, M. 1936. Chironomidae of Japan (Diptera), VII New species and a new variety of the genus Chironomus Meigen. - Philippines Journal of Science 60: 71-85+ 4plates. 
Webb, C.J. and Scholl, A. 1985. Identification of larvae of European species of Chironomus Meigen (Diptera: Chironomidae) by morphological characters. - Systematic Entomology 10: 353-372. DOI: http://dz.doi. org10.1111/j.1365-3113.1985.tb00143.x.

Wülker, W. 1980. Basic patterns in chromosome evolution of the genus Chironomus (Diptera). - Zeitschrift fur zoologische Systematik und Evolutionsforschung 18: 112-123. DOI: http://dx.doi.org/10.1111/j.1439-0469.1980. tb00733.x

Wülker, W. and Morath, E. 1989. South American Chironomus (Dipt.) - karyotypes and their relations to North America. - Acta Biologica Debrecina Supplementum Oecologica Hungarica 2: 389-397.

Article submitted 5. January 2017, accepted by Torbjørn Ekrem 11. May 2017, published 12. May 2017. 